\title{
Investigating carnivore guild structure: Spatial and temporal relationships amongst threatened felids in Myanmar
}

\author{
Pyae Kyaw ${ }^{1}$, David Macdonald ${ }^{1}$, Ugyen Penjor ${ }^{1}$, Saw Htun ${ }^{2}$, Hla Naing ${ }^{2}$, Dawn Burnham ${ }^{1}$, \\ Żaneta Kaszta ${ }^{1}$, and Samuel Cushman ${ }^{1}$ \\ ${ }^{1}$ University of Oxford Wildlife Conservation Research Unit \\ ${ }^{2}$ Wildlife Conservation Society Myanmar Program
}

December 16, 2020

\begin{abstract}
At least nine felid species can co-occur in Southeast Asia, thus providing an unusual opportunity to investigate poorly known guild structure and the factors controlling it. Using camera-trap data, we quantified space use, temporal activity, and multidimensional niche overlap of tiger, clouded leopard, marbled cat, leopard cat, and Asiatic golden cat in Htamanthi Wildlife Sanctuary of Myanmar. We hypothesized that the spatio-temporal behaviour of smaller cats can reflect avoidance of the larger cats, which are both potential competitors and predators, and similar-sized guild members would partition their niches in space or time to reduce competition for resources. Our approach involved single-species occupancy modelling to identify site covariates, pairwise spatial overlap using Bayesian inference, and activity overlap with Kernel density estimation and multivariate analyses to test hypotheses. We found tiger and marbled cats were primarily diurnal, clouded leopard and leopard cat were nocturnal and golden cat exhibited cathemeral activity. We observed a complex pattern of guild assembly and potential competition involving strong niche displacement between the golden cat and marbled cat, but high overlap between the relatively similarly-sized pairing of clouded leopard and golden cat, and the markedly differently-sized tiger - golden cat pairing. No significant evidence of mesopredator release was observed and the felid assembly in Northern Myanmar appeared to be partitioned mainly on a spatial, rather than temporal, dimension. Nonetheless, the temporal association between the three mesopredators was inversely related to the similarity in their body sizes. The insights into this felid guild revealed that the largest niche differences in the use of space and time occurred between the three smaller species, most evidently between the Asiatic golden cat-marbled cat pairing, followed by marbled cat - leopard cat pairing. This study offers new insight into carnivore guild assembly and, adds substantially to knowledge of five of the least known felids of conservation concern.
\end{abstract}

\section{Hosted file}

KYAW_et.al_Spatial and temporal relationships amongst threatened felids in Myanmar.pdf available at https://authorea.com/users/383344/articles/499232-investigating-carnivoreguild-structure-spatial-and-temporal-relationships-amongst-threatened-felids-in-myanmar 